\title{
QU
}

\section{EXPLORAÇÃO DE QUESTÕES DO ENEM PARA UM MELHOR DESEMPENHO DOS ALUNOS NO EXAME NACIONAL DO ENSINO MÉDIO}

\author{
Wênia K.T.Silva ${ }^{1}$; Antônio L.T.Barbosa²; Suzana Maria Alves de Souza Reinaldo³; Paulo \\ Roberto Nunes Fernandes ${ }^{4}$; Leonardo Alcantara Alves ${ }^{4}$; Luciana Medeiros Bertini ${ }^{4}$ \\ ${ }^{1}$ Licenciando em Química - do IFRN - Campus Apodi - e-mail: weniakaline2009@hotmail.com \\ ${ }^{2}$ Licenciando em Química - do IFRN - Campus Apodi - e-mail: leodecio_1@hotmail.com \\ ${ }^{3}$ Docente Da Escola Estadual Professor Antônio Dantas; e-mail: susanareinaldo@hotmail.com \\ 4, Docente do Instituto Federal de Educação, Ciência e Tecnologia do RN, Campus Apodi, e-mail: \\ paulo.fernandes@ifrn.edu.br; leonardo.alcantara@ifrn.edu.br; luciana.bertini@ifrn.edu.br
}

\section{RESUMO}

O Exame Nacionial do Ensino Médio (Enem) tem como objetivo principal avaliar o desempenho do estudante ao fim da escolaridade básica. O Exame é disponibilizado, anualmente, para alunos de escolas públicas e privadas nas 27 unidades federativas. Desta forma, o presente trabalho foi realizado de acordo com os conteúdos visto durante sua formação no Ensino Médio em sala de aula, com o intuito de integrar os conteúdos da 1a à $3 \underline{a}$ série do Ensino Médio. As questões foram obtidas a partir de edições de ENEMs anteriores pelos bolsistas de iniciação a
Docência (PIBID), com o intuito de trazer uma maior realidade de como são abordadas as referidas questões. Foi observado que os alunos tiveram um bom desempenho na resolução das questões, onde eles revisaram alguns conteúdos e viram como as questões são abordadas. A exploração dessas questões na preparação do aluno para o ENEM é de grande importância, pois assim, o aluno se familiarizou como o modo que o exame é aplicado, obtendo-se assim, uma melhor aproveitamento na prova.

\section{ESMS OF ISSUES EXPLORATION FOR BEST PERFORMANCE OF STUDENTS IN HIGH SCHOOL EXAMINATION OF NATIONAL}

\begin{abstract}
The high school Nacionial Examination ( Enem ) has as main objective to evaluate the student's performance at the end of basic education. The exam is offered annually to students from public and private schools in 27 units. Thus, this study was performed in accordance with the contents seen during their training in high school in the classroom, in order to integrate the contents of the 1st to 3rd year of high school. The questions were obtained from previous editions by ENEMs initiation scholarship to
\end{abstract}

Teaching ( PIBID), in order to bring greater reality of how these issues are addressed. It was observed that the students performed well in resolving issues where they reveram some previous content and seen how the issues are addressed. The exploration of these questions in preparing the student for the ESMS is of great importance, as well, the student became familiar as the way the test is applied, thus obtaining a better use in the race.

KEY-WORDS: ENEM, Integrate, Utilization 


\section{EXPLORAÇÃO DE QUESTÕES DO ENEM PARA UM MELHOR DESEMPENHO DOS ALUNOS NO EXAME NACIONAL DO ENSINO MÉDIO}

\section{INTRODUÇÃO}

A educação básica no Brasil ganhou contornos bastante complexos nos anos posteriores à Constituição Federal de 1988 e, sobretudo, nos últimos oito anos. A educação básica é um conceito, definido no art. 21 como um nível da educação nacional e que congrega, articuladamente, as três etapas que estão sob esse conceito: a educação infantil, o ensino fundamental e o ensino médio (CURY, 2002). $O$ art. 22 estabelece os fins da educação básica: a educação básica tem por finalidade desenvolver o educando, assegurar the a formação comum indispensável para o exercício da cidadania e fornecerIhe meios para progredir no trabalho e em estudos posteriores.

O Enem foi criado em 1998 com o objetivo de avaliar as competências básicas para o exercício pleno da cidadania e como uma "modalidade alternativa ou complementar aos exames de acesso aos cursos profissionalizantes pós-médios e ao ensino superior" (BRASIL, 1998, p. 2). Assim, o exame viria em direção distinta do modelo vestibular posto, tornando-se uma forma alternativa de ingresso na educação superior.

Um resultado importante, proveniente de algumas pesquisas, é que o desempenho dos estudantes é baixo ou muito baixo em relação a Ciências da Natureza no Enem. Como a média dos alunos na Escola Estadual Professor Antônio Dantas no Exame é de 458,728 pontos, tendo em vista essa média baixa, o presente trabalho teve como objetivo incentivar os alunos a estudarem com mais intensidade para assim, obter uma melhor nota e conseguir ingressar no ensino superior.

\section{METODOLOGIA}

O projeto foi desenvolvido na Escola Estadual Professor Antônio Dantas no município de Apodi- RN com alunos do 3 " $D$ ” série do Ensino Médio do turno matutino. A turma continha 28 alunos, em que os mesmos eram atendidos pelo Programa Institucional de Bolsas de Iniciação a Docência (PIBID) do curso de Licenciatura em Química do Instituto Federal de Educação do Rio Grande do Norte (IFRN), Campus Apodi. 4a Semana de Química - IFRN, 2016 
O trabalho foi realizado de acordo com os conteúdos visto durante sua formação no Ensino Médio em sala de aula, com o intuito de integrar os conteúdos da 1a à $3 \underline{a}$ série do Ensino Médio. Foi realizado um levantamento de 18 questões a partir das edições anteriores do ENEM pelos bolsistas do PIBID que abordassem todos os níveis de Química com intuito de relacionar e relembrar os assuntos já vistos nos anos anteriores. 0 objetivo era de aproximar os estudantes da escola com a realidade de como são abordadas as referidas questões e revisar conteúdos já trabalhados.

As questões foram apresentadas aos alunos em forma de slides, estipulando um tempo de 5 minutos para que eles pudessem obter a resolução. Logo após, foi feito a explanação da questão, obtendo assim o resultado final. As apresentações foram feitas em sala de aula no horário das aulas de Química.

\section{RESULTADOS E DISCUSSÃO}

Durante a aplicação da atividade, os alunos se demonstraram bem interessados e participativos. Houve uma grande participação das turmas, visto que grande a maioria dos alunos visam ingressar na faculdade através do ENEM. Alguns momentos foram registrados por fotografias como pode ser observado na Figura 1.

Figura 1: Fotografia dos discentes na apresentação das atividades
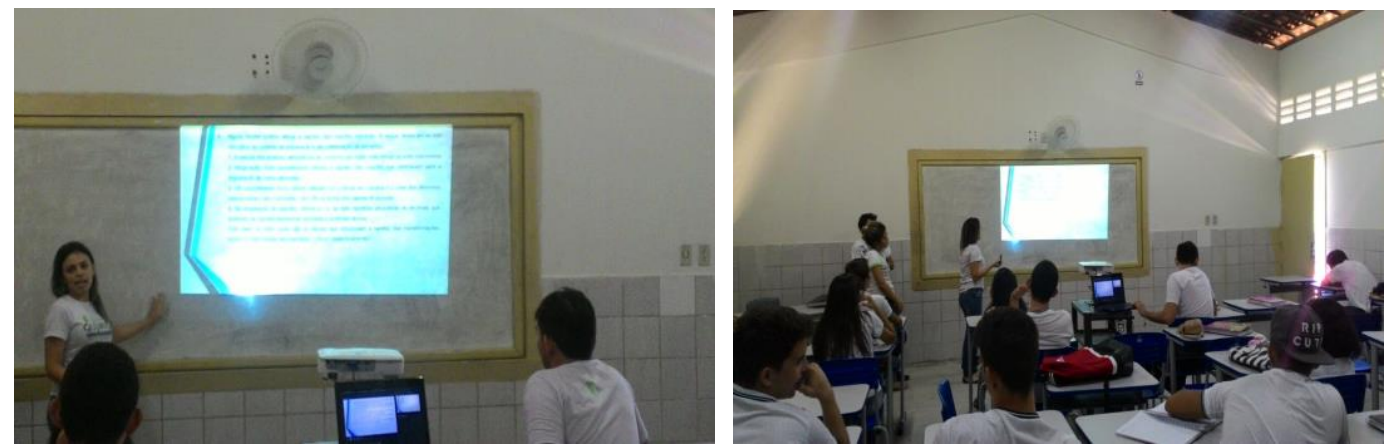

Fonte: Próprio autor

A turma teve um nível de $76 \%$ de acerto das questões. Apesar das questões estarem bastante diversificadas, o conteúdo que mais prevaleceu foi estequiometria, pois através dele era possível resolver diversas questões. O nível de acertos foi mais satisfatório nos conteúdos do 30 ano, possivelmente por serem os mais recentes estudados.

Após a aplicação dessa atividade, os alunos puderam ter uma preparação prévia para o exame, em relação ao tipo de questões abordadas e tempo de resolução. Após 4a Semana de Química - IFRN, 2016 
esta atvidade foram aplicados questionários na turma. O objetivo do questionário era avaliar os conhecimentos antes e após as atividades aplicadas.

Após a aplicação do questionário, foi feito um levantamento de dados obtendo-se a porcentagem de cada questão. Na primeira questão foi perguntado se o aluno almeja ingressar no ensino Superior, em que $11 \%$ disse que não e $89 \%$ que sim. Desta forma, observa-se que a maior parte dos alunos desejam ingressar na faculdade.

$\mathrm{Na}$ segunda questão, foi questionado as maiores dificuldades encontradas nas questões de Químicas abordadas pelo Exame: interpretação das questões, alto nível das questões ou extensão das questões. Foi obtidas as seguintes médias, $82 \%$ disse que tem maior dificuldade em interpretar as questões, $11 \%$ foi o alto nível das questões e $7 \%$ a grande extensão das questões. É possível notar uma dificuldade na disciplina de Lingua Portuguesa visto que o processo de interpretação está relacionado com essa matéria gerando assim um impedimento na resolução de outras disciplinas.

E para finalizar o questionário foi indagado quais as contribuições dessa atividade realizada pelos bolsistas do PIBID. A partir desta metodologia, a maioria dos alunos dividiram-se entre $54 \%$ com o relembrar os conteúdos das séries anteriores e $39 \%$ a familiarização com o modo em que as questões são abordadas no Exame e apenas 7\% disse que não teve nenhuma contribuição. Os dados obtidos foram satisfatórios, indicando as principais contribuições recebidas pelos alunos após a abordagem das questões de Química do Enem.

\section{CONCLUSÃO}

Diante da atividade realizada com os alunos do Ensino Médio beneficiados pelo Programa PIBID na Escola Estadual Professor Antonio Dantas, entende-se que a exploração dessas questões na preparação do aluno para o ENEM é de grande importância, pois assim, o aluno pode se familiarizar o modo que o exame é aplicado, obtendo-se assim, uma melhor aproveitamento na prova. 


\section{AGRADECIMENTOS}

A Escola Estadual Professor Antônio Dantas, pelo espaço de desenvolvimento do programa PIBID, e a CAPES pelas Bolsas ofertadas aos integrantes do programa PIBID do IFRN - campus Apodi.

\section{REFERÊNCIAS}

BRASIL. Instituto Nacional de Estudos e Pesquisas Educacionais Anísio Teixeira (Inep). Enem: documento básico. Brasília, 1998.

CURY, Carlos Roberto Jamil. A educação básica no Brasil. Educ. Soc., Campinas, vol. 23, n. 80, p. 168-200, 2002.

VIGGIANO, Esdras; MATTOS, Cristiano. O desempenho de estudantes no Enem 2010 em diferentes regiões brasileiras. Rev. Bras. Estud. pedagog. (online), Brasília, v. 94, n. 237, p. 417-438, maio/ago. 2013. 